\title{
Ceruminous Neoplasm
}

National Cancer Institute

\section{Source}

National Cancer Institute. Ceruminous Neoplasm. NCI Thesaurus. Code C5558.

An adenoma or carcinoma that arises from the ceruminous glands in the external auditory canal. 